\title{
Special Collections Exhibitions: How They Pay Dividends for Your Library
}

\begin{abstract}
A successful library exhibition is usually seen as one that attracts large numbers of visitors and improves their knowledge of a topic. The ways that exhibitions benefit library staff, library collections, and library operations are much less frequently considered. Though secondary, these internal outcomes are an important part of how libraries profit from exhibitions, in the same way that stock dividends supply a substantial percentage of overall investment returns. This essay views exhibition curatorship as a form of professional and organizational development and calls attention to how it helps librarians develop skills, knowledge, resources, and relationships that enhance library services and staff careers. Librarians at small-and medium-sized institutions without professionally trained exhibitions staff are the target audience, but the perspectives outlined here are broadly relevant.
\end{abstract}

If you curated a major library exhibition and no one came to see it, would you have wasted your time?

As strange as it may sound, asking an existential question like this is a good exercise in deepening our professional appreciation for the benefits exhibitions bring. It is natural and logical to place public learning outcomes at center stage when evaluating an exhibition's success or failure, and an exhibit without visitors would undoubtedly have been time misspent. That said, in focusing on how exhibitions measure up in the public eye, we should not overlook how they inform and advance other aspects of our work in special collections, work that indirectly benefits the public on many levels.

I began thinking about my own response to this question several years ago after overhearing a remark about how the exhibition program in the library where I worked at the time was not bringing in enough "foot traffic." Even though attendance was rising and the library was offering more exhibitions-related programming than ever before, I certainly had no objections to seeing more people come through our door. At the same time, I felt that such a one-dimensional definition of success would not capture everything the library's exhibitions were achieving, nor did I want it to become the only standard by which exhibitions were judged. Having worked behind the scenes on more than a dozen exhibitions, I could think of many 
good things that had come out of them, both for myself and others and the library as a whole, which would have happened regardless of the number of visitors we tallied on our log sheet. Weighing that comment led me toward a clearer understanding of the "hidden" outcomes of library exhibitions - outcomes that anyone whose job involves planning or advocating for exhibits should emphasize at every turn.

With so many competing demands on our time and resources, it may be tempting to place exhibitions low on the list of priorities or to reduce the amount of work put into them. How often, though, do librarians take a holistic view and fully consider what exhibitions contribute not only to the communities we serve, but also to our inner growth as professionals and to the inner workings of our institutions? In other words, how do exhibitions benefit library staff, library collections, and library operations in addition to library users? From this perspective, exhibitions offer many rewards besides their principal one of engaging and educating the public. Anyone familiar with the stock market knows that savvy investors prefer stocks that pay large dividends-money you get simply for owning a stock—even when share values decline. Such stocks buffer investors' portfolios and deliver returns no matter how good or bad the market is performing. Think of exhibitions in the same way. Though high returns in the form of an impressive gate count and meaningful visitor experiences is obviously every exhibition curator's primary goal, the dividends exhibitions pay on the side merit attention, too.

Unfortunately, because exhibition dividends are mostly qualitative, providing a detailed cost-benefit analysis for them is nowhere near as easy as analyzing quantifiable stock dividends. In one sense, this is a minor concern-they are bonuses that cost nothing more than what it would already cost to design and promote a large, high-quality exhibition with the public benefit in mind. Furthermore, because many of the most significant internal outcomes of library exhibitions are cumulative and rarely start flowing in all at once, it is unlikely that the time and effort involved in formally assessing them will itself be worth the cost. The professional literature on exhibitions in special collections, or even in museums, has paid only passing attention to the soft benefits of exhibition planning that I have tried to compile a list of here; it is also quite open-ended about how to assess them, partly for the reasons I mention above. ${ }^{1}$ The development of practical standards for a

1. Major works that discuss exhibition assessment include: Jessica Lacher-Feldman, Exhibits in Archives and Special Collections (Chicago, Ill.: Society of American Archivists, 2013); Mary E. Brown and Rebecca Power, Exhibits in Libraries: A Practical Guide (Jefferson, N.C.: McFarland, 2006); "Standards for Museum Exhibitions and Indicators of Excellence," American Association of Museums (website), available online at https: / / www.name-aam.org/resources [accessed 15 July 2018]; Dorothy Fouracre, "Making an Exhibition of Ourselves? Academic Libraries and Exhibitions Today," Journal of Academic Librarianship 41, no. 4 (2015): 377-85; Emma Howgill, "New Methods of Analysing Archival Exhibitions," Archives and Records 36, no. 2 (2015): 179-94; Manual of Museum Exhibitions, eds. Barry Lord and Maria Piacente (Lanham, Md.: Rowman \& Littlefield, 2014); Leslie Bedford, The Art of Museum Exhibitions: How Story and Imagination Create Aesthetic Experiences (London, U.K.: Routledge, 2014); Polly McKenna-Cress and Janet Kamien, Creating 
comprehensive assessment of exhibitions is a worthy research goal and perhaps one that RBM's readers should embrace-but it is not the purpose of this essay, which is simply intended to stimulate conversation about exhibition curatorship as a form of professional and organizational development. Even if such standards existed, I believe that, for the majority of special collections librarians, acknowledging and emphasizing the internal benefits of exhibitions up front, using them to guide the planning process, and simply allowing them to raise confidence that exhibitions are worthwhile, is good practice. Michael Belcher, an authority on museum exhibitions, comments: "What constitutes an effective exhibition will depend on the viewpoint, be it of the museum or of the visitor, and what it achieves for them."2 The statement applies to libraries equally well.

\section{Learning Labs for Librarians}

There is an old saying that "To do two things at once is to do neither." While that may be a good rule of thumb, it is not absolutely true. In helping others learn about a topic, exhibition curators are expanding their own knowledge and professional skillsets. Instead of viewing exhibition galleries as public spaces, we could just as easily see them as learning labs where, through the process of curating exhibitions, librarians develop expertise that is useful later on. Whether they do this on their own or in collaboration with formally trained exhibitions professionals, the outcomes should be the same. ${ }^{3}$

Having enough time to learn about the contents of our collections in great detail is unfortunately a luxury not all librarians enjoy. One of the most attractive dividends that exhibitions pay is that they give library staff a dedicated amount of time to explore the materials in their care, as well as an excellent reason to do so. Though any staff member who visits an exhibition will take something away from it, if only a vague memory that the library has holdings in that area, the curator in particular will develop knowledge of what is on display and be a point of contact when questions regarding those materials come up in the future.

These might include answering in-depth reference inquiries, talking to students, donors, or other visitors about materials from the exhibit, training new employ-

Exhibitions: Collaboration in the Planning, Development, and Design of Innovative Experiences (Hoboken, N.J.: Wiley, 2013); Beverly Serrell, Judging Exhibitions: A Framework for Assessing Excellence (London, U.K.: Routledge, 2017); John H. Falk and Lynn Dierking, The Museum Experience (London, U.K.: Routledge, 2016).

2. Michael Belcher, Exhibitions in Museums (Washington, D.C.: Smithsonian Institution Press, 1991), 201.

3. According to a 2010 ARL survey, "Only 22 percent of institutions have a staff member for whom exhibitions are a primary responsibility. Postings between 2012 and February 2015 at the ARL Position Description Bank Project, which aggregates position descriptions posted by its member libraries, includes only 20 positions at seven institutions whose primary job responsibility is exhibition work." Amy H. Chen, Sarah Pickle, and Heather L. Waldroup, "Changing and Expanding Libraries: Exhibitions, Institutional Repositories, and the Future of Academia," in The Process of Discovery: The CLIR Postdoctoral Fellowship Program and the Future of the Academy, eds. John C. Maclachlan, Elizabeth A. Waraksa, and Christa Williford, CLIR Pub 167 (Sept. 2015), 62-81. 
ees, and developing specific outreach strategies. Whether the exhibit curator is personally responsible for acquisitions or can recommend purchases to someone else, searching for materials to display often casts light on logical areas for collection development. What's missing? What would help tell this story better? Is there enough local interest to justify developing a new collecting area? The process of crafting an exhibition can point out the answers to questions like these.

The theme of the 2017 RBMS Preconference was "The Stories We Tell." Great storytelling skills, the speakers emphasized, must be a part of every special collections librarian's toolkit. Valerie Hotchkiss ended her opening plenary by quoting Rudyard Kipling, who believed that "If history were taught in the form of stories, it would never be forgotten." An exhibition is a terrific place to cultivate the skill of telling stories that stick in people's minds. Regardless of attendance, the curator will have learned something about communication that can be applied to other aspects of his or her job. For example, curating an exhibition teaches those with a highly academic background how to present information to a general audience. Developing an accompanying activity for children can likewise be an exercise in adapting a story for people with different levels of knowledge.

Another skill that exhibition planning nurtures is the ability to convey the essential facts in a few words. Librarians can apply this to other things that they write: grant proposals, press releases, blog posts, training manuals, even finding aids. Having staff who know how to craft a compelling story also positions them to work with donors. Dull facts and figures rarely inspire people with money or collections to give. Though donors give for many reasons, being touched by stories that connect to their own experiences or values is one of the most common. It is worth observing, too, that exhibitions provide stories in and of themselves about how library collections make a difference-stories that can be told again and again to potential supporters and partners.

I strongly believe that curating exhibitions makes librarians better teachers. Apart from becoming more adept at learning about unfamiliar subjects, my own work with exhibitions has helped me understand different learning styles. While some people learn best through self-paced reading, some learn visually, aurally, or in a group setting. For others, observing similarities and differences or even playing a game is helpful. ${ }^{4}$ That knowledge has, in turn, led me to rethink the way I engage students in the classroom. Having searched for materials to include in exhibits, I have also gained a valuable perspective on the research process that informs my approach to library instruction. I have learned, for example, that sometimes one is better off using what is at hand rather than devoting an excessive amount of time to searching for the perfect source.

4. Maria Piacente and Christina Sjoberg, "Interpretive Planning," in Manual of Museum Exhibitions, eds. Lord and Piacente, 251-68. 
Another lesson that exhibitions have taught me that I try to pass on to students is the fact that library collections are more multipurpose and multidisciplinary than they may appear. Flexibility, resourcefulness, persistence, a readiness to look in unexpected places, and the ability to see connections are skills I have honed by working on exhibitions. When I find myself trying to foster those skills in students encountering primary sources for the first time, the exhibitions I have curated provide examples of how to overcome the hurdles researchers face.

Other professional skills librarians cultivate by curating exhibitions include becoming better writers, critical thinkers, and public speakers. Some have reported gaining experience in managing issues involving controversy, intellectual freedom, freedom of expression, and library neutrality. ${ }^{5}$ Tight deadlines are often part of the work, meaning that everyone involved in exhibitions learns something about time management. If library staff develop audio tours, promotional videos, or other digital components to an exhibit, greater expertise with technology and software can be yet another positive takeaway. ${ }^{6}$

\section{Supporting Reference, Instruction, and Outreach}

One downside to exhibitions is that they are inherently temporary. Considering the amount of time and money that goes into them, librarians who want to stretch their investment and earn further dividends might think about ways to preserve an exhibit's descriptive content after the physical display comes down. Because of their usefulness as reference tools, exhibition catalogs are ideal products if your institution can afford them, but there are cheaper alternatives that still provide many of the same benefits in terms of getting extra mileage out of your work. Putting in-house exhibitions online is perhaps the best, for (despite hidden costs) it makes the content permanently available to both local and nonlocal researchers. However, depending on the situation, some may find reason simply to develop a workable method of filing exhibit labels or checklists at the reference desk to aid future researchers; doing this for labels could get somewhat messy because of the need for metadata, but cataloging a checklist is easily done and even an imperfect system of preserving descriptive content is better than nothing.

As mentioned above, an exhibition is an opportunity to educate library staff about what your collections hold and why those materials are significant. Even staff

5. Gwendolyn J. Reece, "Multiculturalism and Library Exhibits: Sites of Contested Representation," Journal of Academic Librarianship 31, no. 4 (2015): 366-72; Mary Kandiuk, "Avoiding Controversy: Academic Freedom and the Library Exhibit," Art Documentation 36, no. 1 (2017): 91-107.

6. For related case studies, see Anna Dysert, Sharon Rankin, and Darren N. Wagner, "Touch Tables for Special Collections Libraries: Curators Creating User Experiences," RBM 19, no. 1 (2018): 41-58; and Brian W. Keith, Laurie N. Taylor, and Lourdes Santamaría-Wheeler, "Broadening Impact for Library Exhibitions and Speakers," Journal of Library Administration 57, no. 4 (2017): 389-405. 
members not involved in planning the exhibit will learn something from it. Reference librarians, in particular, will gain a better awareness of sources to recommend to researchers. Lack of knowledgeable staff, it goes without saying, can adversely affect customer service. Exhibitions are one way for staff, as well as outside experts, to share knowledge with each other. For new hires, who may feel frustrated at not being as familiar with a library's collections as more experienced personnel, exhibitions can be a component of staff training. Provided that the item labels and checklists are retained, they can also curtail the loss of knowledge when employees retire or move on to new jobs. An exhibition need never completely disappear just because it is no longer on display.

Library staff can also reuse exhibit labels and checklists to prepare for class visits. Identifying items to show on these occasions and coming up with comments is often no small task. Having ready-made notes and lists on hand will save time. Instructional materials developed for the exhibit can be repurposed in the same way for future classroom use; it is not uncommon, moreover, for exhibit curators, in working closely with collection materials, to find inspiration for new classroom activities involving primary sources.

Given the ongoing popularity of object-based learning, libraries can sometimes find it hard to accommodate the large number of requests to visit special collections, especially when those requests come from lecture courses with enrolments in the hundreds. Exhibitions can help. As long as the exhibit space is big enough, recommending that classes with a very high number of students visit the exhibition instead of having a customized class session can relieve some of the demands on library staff and facilities. A lecture course with several hundred students could visit in individual course sections, with a librarian making a few introductory remarks and then inviting the students to explore the items on display. Optional visits outside of class could be considered as well. Though substituting passive for handson instruction should obviously not be made a regular habit, there are times when an exhibit is self-explanatory and could stimulate a later class discussion or activity such as a reflective essay.

Do you ever struggle to come up with material for social media posts? Is it hard to maintain a regular schedule of posts? Once again, exhibitions can come to your aid. Since the curator has already identified eye-catching items and written labels, recycle some of those labels for social media. It can be as simple as modifying a few sentences and snapping a photo or two. Not only will this save time and put an exhibit to extra use, it will also help the library build a public following, gauge interest in a topic, and make the information available online. 


\section{Supporting Technical Services}

The behind-the-scenes benefits of exhibitions extend to technical services as well. In researching materials to display and writing item descriptions, exhibition curators sometimes spot ways of improving catalog records. These might include correcting simple errors, adding new subject headings, or making note of overlooked copy-specific information, such as inscriptions or provenance. With archival collections, in particular, exhibitions may shed light on inadequately described content. For example, an exhibition related to women's history would likely involve looking for material in collections named after men, institutions, or organizations-collections where women's history is almost always present but may not have been highlighted for whatever reason during cataloging. Depending on what is found, the exhibition may provide the impetus to rewrite or expand the finding aid.

Curatorial review stemming from an exhibition can also pay off in regard to conservation and basic collection maintenance. In my own experience as an exhibition curator, I have discovered badly shelved or missing books, folders out of order, and items needing better housing or repairs, all while browsing for materials to display. Preparing items to go into exhibit cases, similarly, can be an opportunity to perform conservation treatments such as mending torn pages or encapsulating brittle items, steps that will benefit the materials long after the exhibition has ended. If a library does not employ or provide access to a conservator, an exhibition can supply a good reason for staff to educate themselves about conservation guidelines and standards. ${ }^{7}$

Exhibitions pay dividends in regard to digital services, too. If the materials on display have already been digitized, the exhibition (whether in-house or online) can draw potential users' attention to a digitization program and market its resources. In other words, exhibits can be the equivalent of storefront window displays. Some exhibitions may not advertise previously digitized material but still yield long-term digital components like online lesson plans, activities, or resource guides; digital humanities projects may grow out of them as well. A popular exhibit might also suggest materials for a library to consider digitizing. Did many visitors ask whether the materials are available online? Did some other need for digital access become clear? Furthermore, if there has already been institutional interest in digitizing a collection, an exhibition may provide evidence of public interest or other data that would make a case for moving forward.

\section{Exhibiting Library Operations and Vision}

Ultimately, a library exhibition displays more than tangible objects. A multidimensional view of exhibitions recognizes that they are an occasion to talk about what librarians do and why supporters should care. While that discussion can be held

7. Michelle Visser, "Considerations in the Preparation of Library Exhibits Featuring Rare Books and Manuscripts," College \& Undergraduate Libraries 11, no. 2 (2004): 51-62. 
anywhere, exhibition galleries are the ideal place to do it because they are a point of convergence for so much of what goes on in special collections that outsiders seldom see. From things like cataloging and conservation to figuring out how to enrich students' academic experience and better serve diverse communities, exhibitions provide an array of talking points. "A business that makes nothing but money is a poor business," Henry Ford once observed. I would modify that a bit and say that an exhibit that shows off nothing but your collections is a poor exhibit or is at least one that could be improved. If a library is not using exhibitions to lead into conversations about larger institutional goals or issues, it is missing a golden opportunity.

There is a common piece of management advice that runs something along the lines of "never assume others know what you do." Even more than others, special collections librarians struggle in this regard. Despite the premise of this article, exhibitions are, in one sense, a risky bet. The idea that people who work in special collections have easy jobs that involve little more than trying to impress visitors with showy objects has diminished in recent years, but it still lingers. In curating exhibitions, we run the risk of sustaining the caricature of rare book librarians and archivists as privileged keepers of a horde of treasure that can only be viewed under glass. As much as possible, then, it is important that librarians approach exhibitions as an opportunity to educate people about the real work we do and why it matters.

One element of this involves showing how library work aligns with priorities of the university administration. In planning, promoting, and reflecting on exhibitions, it can be worth asking a question like: What keeps the president and provost up at night, and what is the library doing to make their jobs easier? For example, if an exhibition significantly contributes to institutional diversity initiatives, let administrators know. The same goes for other goals like attracting and retaining great faculty and students, generating revenue through gifts or grants, helping students find jobs, supporting extended education, and demonstrating the value of higher education. Connecting the dots between these "big picture" objectives and a library exhibition may repay the effort.

Establishing a vision for our collections and services is something librarians all invest a lot of time and energy in. Still, the way we see ourselves is not necessarily how others see us. A recent study undertaken for the Council on Library and Information Resources (CLIR) observes that "By producing exhibitions, special collections staff can produce their own narrative of the value of their collection...." How this takes shape varies widely but may include portraying ourselves as "producers of research rather than just collectors of research." ${ }^{8}$ No matter how a library defines the value of its collections - a definition that changes, based on context-exhibitions will bring that narrative to the wider world's attention.

8. Chen, Pickle, and Waldroup, "Changing and Expanding Libraries," 70. 


\section{Relationships}

Another major way that exhibitions build on themselves is by fostering relationships. Even after an exhibit has ended, it is likely the people it brought together will continue to seek each other out well into the future. As Carole Ann Fabian, Charles D’Aniello, Cynthia Tysick, and Michael Morin have pointed out, exhibits can be "an enjoyable and effective focal point around which to build relationships ... and set the stage for collaborations and interactions having little in common with the events that initiated them."

At the top of the list of relationships that exhibitions foster are those between library staff and library users. Faculty, students, researchers, and community members, on the one hand, learn from librarians about local holdings. Librarians, in return, learn from users about subject matter and receive feedback about how the collections can be of service.

Rapport with donors, of course, occasionally results from major exhibitions. Sometimes this stems from donors having been impressed by a library's collections, services, facilities, and staff. An exhibition might also highlight a need that a donor might be able to fill, whether by providing collections, funding, or some other form of support. It is important to include current students in the category of potential donors. As alumni, they may one day be in a position to give. Exhibitions also offer prospective donors who did not graduate from your institution a reason to visit campus. ${ }^{10}$ Equally important are the relationships exhibits establish between librarians, development officers, and volunteer organizations such as a Friends of the Library group. Coming together around an exhibition that has been connected to a larger fundraising goal may help each party learn how to work with the others to achieve results.

The same is true for relationships with colleagues in general. From the initial planning stages to tidying up after the show is over, curating an exhibition is a complex and sometimes stressful operation. It can be as much an exercise in teamwork and good management as in educating the public. Who excels at what? Which staff members work well together? Which do not? What is the best way to communicate clearly and ensure goals are met? Is extra tact needed when critiquing someone's work? What does a particular employee need to be productive, successful, and happy? Independence? Guidance? Deadlines? Knowing the answers to these questions may inform one's overall approach to working with colleagues.

9. Carole Ann Fabian, Charles D’Aniello, Cynthia Tysick, and Michael Morin, "Multiple Models for Library Outreach Initiatives,” Reference Librarian 39, no. 82 (2004): 39-55.

10. Brian T. Allen, "Constituencies of an Academic Art Museum," in A Handbook for Academic Museums: Beyond Exhibitions and Education, eds. Stefanie S. Jandl and Mark S. Gold (Edinburgh, U.K.: Museumsetc, 2012), 262-65. 
When it comes to strengthening relationships between special collections staff and coworkers in other parts of the library, here, too, exhibitions are a way of diversifying a broader strategy. Many special collections librarians have encountered colleagues in other library units who seem to have little awareness of primary sources and the academic literacies they support. A weak relationship in this regard can present a further challenge by negatively impacting the ability of special collections staff to secure internal resources. Though bridging this gap requires a multifaceted and sustained approach, inviting colleagues to collaborate on an exhibition is a place to start. It can help librarians outside of special collections increase their appreciation for local resources and, through personal experience, strengthen their understanding of why nonelectronic sources are important. This form of "inreach" can also bring in expertise that may otherwise be lacking and allow special collections staff to take advantage of existing relationships between subject librarians and the departments or communities they serve.

Other important relationships that exhibits support include those with booksellers. In my work in collection development, I have more than once had dealers contact me and recommend materials for acquisition after having seen announcements of exhibitions on the library website, via social media, or elsewhere. In one case, an exhibition advertised a new collecting area. Realizing he could be of help, a bookseller offered several items to my library that he had not yet listed for sale and that I was happy to purchase.

In addition to relationships between individuals, exhibitions can initiate new or stronger relationships with organizations, institutions, and campus offices. Inviting a $\mathrm{K}-12$ group or local club to view an exhibit, for example, may lead to return visits, while partnering with a community organization to bring in a speaker or guest curator may likewise inspire something bigger. Though loaning collection materials to museums, historical societies, and other libraries can be logistically challenging, it can also bring rewards, such as expanding a library's audience or providing a bargaining chip for requesting loans in return. Working with the media can be equally challenging; but, once again, successful contacts with someone in university media relations, a newspaper reporter, or a writer for a local magazine will probably cause them to remember your name, making it easier to spread the word about library collections and events.

Some relationships are easier to build than others. One obstacle libraries sometimes face is an outdated or inaccurate image of their mission and/or collecting areas. This can happen with anybody but especially with senior faculty or older alumni who recall institutional priorities, policies, or arrangements from earlier times and circumstances. ${ }^{11}$ Another obstacle is a legacy of negative relations between the

11. Allen, "Constituencies of an Academic Art Museum," 260.

Fall 2018 | Volume 19, Number 2 
library or its parent institution and a particular individual, department, or community. Exhibitions offer a potential fix. A thoughtfully designed, well-advertised exhibition is one of the best ways to show how a collection has grown, evolved, or been reoriented. It also underscores the emphasis on teaching and public engagement that special collections librarians now place at the forefront of their mission. Goals such as demonstrating a commitment to diversity and inclusion, indigenous perspectives, or voicing goodwill toward a group that may have been marginalized in the past can be achieved, in part, through exhibitions. They can also signal enthusiasm for a subject, both before and after a donation, opening the door to all kinds of future relationships.

\section{Supporting Staff Careers}

Along with offering clear benefits for the library, exhibitions benefit the careers of library staff members. For some, it can be easy to get boxed into a narrow routine or set of responsibilities. Young professionals in particular can become frustrated when they want to take their careers to the next level but have trouble acquiring experience in areas outside of their job descriptions. Assigning someone to work on an exhibition is one way for managers to be mentors and help their employees grow as professionals. For example, someone who is primarily responsible for cataloging might struggle to broaden his or her experience with outreach, instruction, conservation, donor relations, or implementing aspects of a strategic plan. Those whose jobs are weighted more heavily toward archives than rare books, or vice versa, might find themselves facing a similar challenge. Participating in exhibition development extends a helping hand by providing an opportunity to learn about tasks and formats that are not necessarily part of one's day-to-day routine.

An exhibition can also be seen as a relatively low-stakes experience that helps earlycareer librarians explore what it takes to be a leader. After all, the skills and traits of a good exhibition curator and a good library manager are much the same. These include the ability to communicate clearly to a wide audience, articulate the importance of library resources, seek buy-in from others, interact with donors and the media, and manage a budget. Other leadership skills it is possible to hone through working on a large exhibition include knowing how to establish objectives, encourage teamwork, rely on staff expertise, deal with conflict, navigate bureaucracy, suggest improvements, and accept criticism. ${ }^{12}$ Not least of all, taking the lead on an exhibition can provide experience advocating for one's staff, one's users, and oneself. Even if an employee never curates another exhibition, these will be crucial skills to have practiced.

12. Erich Zuern, "Financial Planning," in Manual of Museum Exhibitions, eds. Lord and Piacente, 373-78; Robert LaMarre, "Effective Exhibition Project Management," in Manual of Museum Exhibitions, eds. Lord and Piacente, 379-91. 
In terms of helping someone develop his or her $\mathrm{CV}$, dossier, or portfolio, exhibition curatorship demonstrates creative activity and engagement with an institution's collections and clientele. This is true not only for library staff but also for the people we collaborate with, including students, interns, and professors. The main display itself, of course, can be listed, but it could easily serve as a launch pad for additional accomplishments such as presentations, conference papers, articles, and other things that might help someone earn tenure or move into a higher position. ${ }^{13}$ Whether or not advancement is a requirement or concern, exhibitions can still enhance job satisfaction and morale. At times, working on an exhibit can offer relief from what may feel like mind-numbing administrative or technical tasks. At others, it can be a chance to learn something new or share one's passion for a subject. Of all the good things that come out of exhibitions, this, to me, is among the most important. After all, if we as librarians aspire to nurture the creative and investigative spirit in others, shouldn't we take steps to keep it alive in ourselves?

\section{Conclusion}

The "hidden" outcomes of major library exhibitions are actually not hidden at all. We just need to adjust our eyes and see them as elements of a cohesive whole. What strategies can librarians adopt to show that, in curating exhibitions, we often accomplish more than we set out to do? A post-exhibition survey is one I have begun experimenting with and recommend. Though intended only for my own use, it helps me collect information, understand how an exhibition may have been particularly effective, and think strategically about how to achieve similar results in the future. Ask questions that encourage people involved with an exhibit to reflect on how it benefited the library on an internal level and contributed to their own professional development. Some benefits will be small and others tentative, but including them in the bigger picture will help spell out the reasons for maintaining and even expanding an exhibition program.

Benjamin Franklin once remarked that "An investment in knowledge pays the best interest." One of our jobs as advocates for library exhibitions is to point out how they enhance knowledge across a broad spectrum that extends well beyond the visitor experience. From there, we can demonstrate why exhibitions, from a library leadership perspective, are a smart place to put money and watch the profits roll in. Fortunately, those profits are not hard to find, and simply making an effort to account for them in the bottom line will make winning the confidence of future investors in knowledge that much easier.

13. For further reading, see Elizabeth A. Novara and Vincent J. Novara, "Exhibits as Scholarship: Strategies for Acceptance, Documentation, and Evaluation in Academic Libraries." American Archivist 8, no. 2 (2017): 355-72; Laurel G. Bowen and Peter J. Roberts, "Exhibits: Illegitimate Children of Academic Libraries?” College and Research Libraries 54, no. 5 (1993): 407-15. 